\title{
Farming, Fishing, and Forestry Occupations
}

National Cancer Institute

\section{Source}

National Cancer Institute. Farming, Fishing, and Forestry Occupations. NCI Thesaurus.

Code C97632.

A class of professional or vocational positions of employment that involve farming, fishing or forestry. 